\title{
Roce adivinatorio mirada remota \\ Lógica musical del sentir en María Zambrano
}

\section{JESÚS MORENO \\ UNED}

\section{La cuestión}

En la lectura de María Zambrano, acaso las mayores dificultades de cornprensión "racional" - aliadas, no tan paradójicamente, como quiero mostrar, a las máximas facilidades de cembebimienton (y para muchos de embobamiento) poético, o tenido por talprovienen de que la escritura de esta pensadora privilegia siempre la forma musical de sus frases sobre la construcción gramatical. Y ello, acaso, no sca ni arbitrio estetizante, ni incapacidad o deficiencia sintáctica, sino explicita voluntad de reconducir el lenguaje, más allá de toda udialéctica". Sea ésta moderna y contemporánea o platónica, y aún más alla de la agonística pre-socrática, en que fermentan ya todos los indicios mito-lógicos que Platón escindirá en dos vias produciendo esa, tal vez, malformación aberrante hasta hoy denominada Filosofía. Desde su primer artículo ("La ciudad ausente», 1928)' $\mathrm{y}$ en modo progresivamente explicito en la indesligable secuencia que forman "Nostalgia de la tierra" (1933), "Por qué se escribe» y $\mathrm{Ha}$ cia un saber sobre el alma (ambos de 1934), Zambrano perfila una escritura que no solo se muestra, sino que se dice, se autointerpreta, como una "lógica del sentir». Y esta "lógica» alcanzará su plena expresión en El hombre y lo divino (1955), Claros del bosque (1977) y De la aurora (1984), libros estos flanqueados, a su vez, por dos hitos: Filosofia y Poesfa (1939) y Notas de un método (1989) que nos señalan con nitidez no sólo los polos gnoseologicos y los géneros literarios en cuestión. sino un tercer elemento decisivo: pues, según aclaración primera de este último libro, tales "notas" lo son wen el sentido musical del términon, y planteándose, a su vez, el interrogante de si se atrevera «a dar la danza del pensamientos.

Por lo tanto enuncio que el problema radical que suscita este modo de escritura es su peculiarísimo estilo fluyente y disolvente de las normas más elementales de las usuales y fijadas retorica y sintaxis. Ofreciéndose, así, unas semántica y semiótica que parecen hacer cuestión, precisamente, de "lo usual" y "lo fijon. Solo en la percepción que podamos alcanzar de este - acaso sólo aparente- atentado contra las normas lingüisticas que nos parecen inviolables, en su dilucidación y explicación, podremos, en realidad, salvaguardar $o$, en su caso, criticar la "forma mentis" zambraniana, sus modos de expresión y los resultados, si es el caso, filosóficos de su obra.

$\mathrm{Y}$ este es el problema a deletrear: por qué esta presunta filosoffa está dicha al son de unos ritmos y una melodía. Por qué de tal escritura podría decirse que es polimitmica, incluso atonal y serial. Induciendo, con ello, al lector a una ardua tarca de recomposición de una recóndita melodía, para cuyo encuentro sólo se le indica un posible método que se presenta como la travesía de las discontinuidades del "sentir". Con el que se pretende disolver y solucionar los nudos a los que el propio entendimiento-voluntad (para 
Zambrano, como para Spinoza, son dos caras de la misma moneda) conducen. Para, acaso, comprender que la filosofía no fue un capricho griego y platónico, sino la más precisa (en el doble sentido) expresión de todo un avatar histórico tenido tanto de pasmo admirativo y de recreación del mundo, como de violenta colonización de la vida, y aun de destrucción, y acaso de progresiva autodevoración, en su paulatino desarrollo, que otros creen que uprogresan.

$Y$ lo primero que hay que señalar, al respecto, es la distinción que Zambrano hace - muy nítida tanto en Claros del bosque como en De la aurora- entre "palabra" como revelación y slenguaje" como expresión animal, o simplemente natural. Dicho de otro modo, entre umanifestación" (palabra-logos-nous) no necesitada del estar envuelta en una relación, sino que siempre la suele romper para crear ámbitos ilimitados, horizontes imprevisibles ${ }^{2} \mathrm{y}$ «expresión", «semilla caída del verbo, que aun estando caida es germinante, fecunda oscuramente ${ }_{3}{ }^{3}$ pero que siempre está envuelta en una relación. A su vez, la palabramanifestación está extendida, dirramos, en un tiempo de plenitud que es "Mirada remota" y musicalidad ("Música calladan de san Juan de la Cruz) que no da lugar a la Historia, sino a la "vida": mientras que son los "ríos del lenguaje" los vinculados a tal historia y los que también tejen su "uso", instrumentalización y colonización. ${ }^{4}$ Por lo tanto, en este sentido hay que entender la doble búsqueda - bien explícita, aunque dicha, siempre, a media voz, y en la penumbra - de "la palabra liberada del lenguaje" y de la palabra sostenida por la musicalidad; pues para esta autora es ésta la que sostiene sobre el abismo a la palabra, la que le permite incluso introducirse en los "ínferos", en las "entrañas" y entresacar a la propia "música" de éstas y cumplir así la tarea que Em- pédocles le asignara: «repartir bien el logos por las entrañas». Y asf encontramos que en el roce con las entrañas la palabra misma emerge musicalmente, según el ritmo y la melodía del que cumple tal acción ( infernal», descenso a sus propios infiernos). $Y$ tal emergencia lo es -y éste parece sea el más recóndito propósito - del propio "rostro". No sólo como imagen, sino en la forma temporal de un "sonar". Y así esta logica del sentir -su "discernir el sentir"busca ser y darse en "lógica musical", naturalmente discontinua, fragmentaria, en series de "roces adivinatorios", «en oleadas que se extinguen, en instantes como centellas de un incendio lejanom; en un persistente juego de «lítotes", de fugaces presencias y significadas ausencias y rastreadas huellas. De apacibles penumbras y de precisión de rumores. En surna, en un intento de alcanzar, con unas razón y escritura idóneas, lo que Zambrano denomina el «logos sumergidon, avasallado por el excesivo afán de violenta claridad de la razón dialéctica. La pura lógica discursiva, el preguntar filosófico, y todo el modo dialéctico y categorial del pensamiento occidental serán discemidos y analizados desde "otra" perspectiva visual y otro modo de oír, errante (por las sinconclusiones" de todo sentir) y a la vez impasible (con, a mi parecer, una lógica preideal, desde el envés de la idea). ¿Valdría para la propia Zambrano lo que ella aplica al pitagorismo?: «Al encontrar su modo de "decir" - musical y no lógico- se restituye a su lugar y a su originaria condición; es ya sí misma; ha sido rescatada". Sin entrar, por ahora, en un análisis de esta peculiar semiótica, o, más clásicamente (y tan fructífero, desde luego en este caso) de las formas retoricas y gramaticales zambranianas, quiero, no obstante, mostrar algunas vinculaciones "miticas" de las concepciones antropológicas y religiosas 
que subyacen a, o se entrecruzan en, esta forma de filosofar. $Y$ tras ello intentaré responder aquella pregunta.

\section{Pathos apolineo-dionistaco y compasion cristiano-sufi}

\section{Invitación a la danza}

Tras el interrogante del libro Notas de un método sobre si atreverse a ofrecer la danza del pensamiento, se esconde un complejo entramado de operaciones, experiencias y reflexiones en torno a la figura bifronte Apolo-Dionisos, $y$ lo que esta figura supone y prolonga en los "misterios" griegos de ancestrales religiones pre-helénicas, como son el dionisismo minoico-micénico, cultos egipcios, el chamanismo, y acaso el más arcaico aún shivaísmo hindú. Dionisos está en juego. $Y$ ese juego es también atendido desde la peculiar perspectiva (luminosa, sonora, lejana, y aun cruel y de particular violencia heridora) apolínea. Naturalmente Nietzsche es el principal invitado a esta -como pretendo mostrar - más que directa interrogación sobre la danza, indirecta, sutil y «práctica» invitación a dar esa forma al pensamiento. Pero a muchos de los pasos de baile nietzscheano, Zambrano les va a oponer una contradanza, justamente con la intención de precisar el sentido originario, arcaico, más allá de las manifestaciones de la Grecia clásica, de los movimientos en juego para bien seguir el son que realmente toca $y$ los roces "divinos" a los que es conveniente adaptar el cuerpo de danza (o para bien danzar, si es que acaso para la vida del llamado Universo, y del hombre en particular, fuese esencial esta compostura danzante). Son buen oido y adecuado movimiento, pues aparecen como ejes del filosofar zambraniano en los que se implican mitos, religiones $\mathrm{y}$ formas artísticas $\mathrm{y}$ de pensa- miento muy arcaicas, cuyas westructuras simbólicas» se persiguen tanto en sentido "filogenético" como wontogenéticon. O dicho de otra manera, en la constelación de figuras de la conciencia humana, en su genealogia y líneas evolutivas en diferentes modos historicos, que, para ella, señalan, aún más allá de su historia, desarrollos esenciales de cada individuo humano, siendo a modo de "señales» e «indicios» de lo que verdaderamente le interesa: cuál sea la configuración de este como imposible ser, tan móvil y fluctuante, y aun sumergido, llamado hombre.

\section{La horadación y transformaciont de la pregunta filosófica}

En la exégesis «divina», o de lo divino, que Zambrano realiza a lo largo de su obra, destaca sobremanera la de la figura de Apolo, así como sus estrechas relaciones con su hermano Dionisos, y las más escondidas con el dios del silencio, los umbrales, el engaño, la ligereza y la muerte, el veloz Hermes. Sin duda al punto central de la explicación teórica zambraniana lo encontramos en El hombre y lo divino, y especialmente en los dos capítulos sobre "Los dioses griegos» $y$ «La piedad". Pero no es menos determinante la aplicación, metafórica y simbolica, que de estos tres dioses se hace en Claros det bosque. Incluso podría decirse que es aquí $-\mathrm{y}$ en múltiples pasajes de De la aurora, y en general en toda la obra posterior a la gran investigación "apolinea» que va a suponer la, en gran parte, inédita Los sueños, el tiempo, y el pensar. llevada a cabo desde 1956 a 1975- donde y cuando Zambrano practica los mismos caracteres que se le atribuyen al dios y a los iniciados en sus misterios. Delfos no es ya tanto una referencia explícita - como en aquel primer libro- sino que se convierte en un horizonte, $y$ 
más precisamente aún, un centro del otr, que es como se define en El hombre y lo divino, y que es lo que a todas luces (a todo ofr) parece querer ser su obra: un medio, tanto más que de visibilidad, de escucha, de atención. Así la ambigüedad, oscuridad, alusividad difícil de extricar, la incertidumbre, el efecto diferido, la violencia transfigurada en gracia, arte y armonía, parecen constituirse en los ejes semántico-semióticos característicos de este filosofar. Más allá ya de una "teorización" sobre los' significados del dios, esta escritura, ella misma, se asienta en esos significados, se erige en sus signos mismos, es sus signos. En un estilo sutil y abigarrado, al tiempo, parece haber querido descender, río de Heráclito abajo, y a través del logos de Empédocles bien repartido por las entrañas, hasta el lugar mismo de la umántica", del oráculo, de la pitonisa. Como si hubiese obedecido estrictamente al pensador de Efeso, cumple sus palabras sobre el «decir» del dios: «El señor a quien pertenece el oráculo que está en Delfos no afirma ni oculta, sino que indicas. $Y$ con este «indican, parece querer cumplir tambien otros designios que trans-greden la extrema polaridad que podríamos situar entre el Tractatus logico-phitosophicus de Wittgenstein y la "razón común" de Heráclito. Pero todos esos otros designios -nuclearizados en torno de la persistente y explicitada ${ }^{6}$ búsqueda de una areligión no sacrificial» - hallan un centro aexpresivon, una forma de decirse, precisamente a través de los caracteres oraculares y adivinatorios de la mántica apolínea. Entre el terror y la gracia, esta forma de pensar desgrana su "razon», que se presenta como procedente de un modo extático de consideración de la realidad, en la que ula filosofia», o el "filosofar", o incluso la Ética subyacente del pensamiento, ocupan el lugar de una mediación entre el más entrañado éxtasis y la más radical distancia, entre -en palabras de Claros del bosque- *algún luggar secreto en la hondonada que recoja el amor herido" 7 y ula mirada remota... una mirada sin intención y sin anuncio alguno de juicio o de proceson. ${ }^{8}$ Sin "categorfas", diriamos entonces. $Y$ ambos lugares - sus extremadas distancias- parecen confluir hacia un punto que es, por modo preciso, el que denomino como "roce adivinatorio", sostenido precisamente por aquel lugar extraterritorial, diriamos, de la Mirada distante. Punto que es aquí el signo mismo del vivir que no representa nada, ni prolifera en la mera «reflexion», en ser categoría refleja, spersonaje" conceptual, sino que, dice Zambrano, "muestra la profecia de la vida alzándose sobre las categorfas que la sostienen y la cercan; que la desgarran también, ya que no alcanzan a contenerla salvándola de su declinar, de ese declinar que lleva consigo todo devenirn." Profecía, vaticinio, pues, alzándose, desde aquella mirada remota, por encina, o tras el modo categorial consagrado por Aristoteles.

Así, parece que el urecinton de donde parte este "filosofar" es un punto solitario de confluencia de dos extremadas distancias que, diriamos, elasticamente vienen a dar, no estrictamente a una pregunta, sino, a un clamor. Del que se dice es: "Un clamor despertado por aquello invisible que pasa sólo rozandom. ${ }^{10}$ Como ha señalado M. Morey (en una reciente conferencia sobre «El interrogar en María Zambranon), el preguntar filosófico de Zambrano se convierte en inter-rogar. Un rogar, seria pues, que es "clamor" donde la "acusación" categorial y su presunta (aunque, desde luego, bien consumada por todo el decir occidental desde Aristóteles) única for ma de enunciación y trato dialéctico con la realidad, la "coseidad", se revierte, más allá de todo juicio, a una obe- 
diencia, es decir, a una docilidad a un saber de oído, a un ob-audire, a un escuchar la misma fícción agónica de la que Platón habla (asi lo recordaba también Morey en aquella conferencia) en la Carta VII, la trágica situación siempre irresuelta del wanhelo" -lo llama así Zambrano- humano situado entre la pura avidez, el "hambre" vital" y unos "oído" $y$ "mirada" remotos que parecieran sostener e inducir ese interrogar. Y ese clamor y ruego despertado - se diría que tan trágicamente... tanto que a la presencia que se oculta, o más bien que en sus ahuellas», según la autora, y en sus wheridas", en las que "ni afirma ni oculta, sino que indicam, no se le puede, o de nada vale, preguntarle, sino a lo sumo clamarle "¿Adónde te escondiste?", como hace san Juan de la Cruz, como mucho antes que el escribieran y declaradamente y exactamente asf, algunos suffes, ${ }^{12}$ por aquello que pasa sólo rozando, parece sea el punto máximo udecible" por el pensar, o de otro modo, el lfmite impenetrable hasta donde la humana razon puede expresar su mismo afán de hacerse reversible. Reversibilidad desde la pura abstracción hasta el intento de ofrecer en palabras la revivencia de la propia escala del pensar que se tiende desde el llamado por Zambrano «sentir originario". En este intento de "revivir", histórica, fenomenológica y vitalmente, el pensamiento, se horadan sus esenciales categorías de espacio y tiempo ( $y$ es obvio que "juego" con un doble sentido de la palabra "horadars, tanto en el sentido del abrir y penetrar espacial, como en el de "dar hora", abrir poros del tiempo). Y con ello parece se quiera permutar radicalmente el sentido de las preguntas filosóficas hasta sus mismas raíces «adivinatorias», hacia "aquello» que inasible, inaprensible, incazable, incategorizable, escurridizo a toda "acusación» 0 "juicion, o voluntad de instrumentacion, es, o señala, no tanto una existencia, cuanto una insistencia. La insistencia de una presencia fugaz que pasa sólo rozando, que se kadivina" como remota mirada. Es en esta insistencia precisamente en la que Zambrano insiste desde sus primeros artículos de los años treinta y con la que, digamos, entra en contacto y la practica -y no sólo delimita $o$ teoriza- como roce adivinatorio. $Y$ establece sus fluencias, sus vaivenes, sus oquedades, sus «intersticios», diríamos deleuzianamente, y sus umbrales, sus distancias o inmediateces, en un ujuego» indiciario $\mathrm{y}$ "horadador» trans-gresivo, y a través de él trans-cendente. Inmanencia y transcendencia, para este pensar, son incomprensibles -o solo recitados emotivos de lugares comunes de cierta sentimentalidad- sin bucear en el juego de complicidades mítico-religiosas, filosóficas y puramente experienciales que hay que establecer para tratar de dar cuenta -y urazón» y uespacio", y "tiempo" en sus gérmenes en el sentir antes de convertirse en wideas", en "categorías", mediante un uso "poeticon, recreador, permanente del logos spermatikos de los estoicos- de esta insistencia del clamor y sus delirios en toda vida humana, a lo largo de toda su historia, en todas las "historias", y naturalmente también en la propia Historia (el cuento, el relato, el mito) de la Filosofia. Con frecuencia he citado el texto de Notas de un metodo ${ }^{13}$ en el que se denuncia la tarea prescisora de la filosofía ede todo en cuanto en verdad ha necesitado para ser», de la reducción que ha realizado con toda aquella parte de la vida que no podia "consumir». Dejándolo -y es una de sus metáforas claves- en «la sombra». Es esta sombra la que va a visitar asiduamente Zambrano, más aún, con la que - tras sus movimientos reversibles por los uinfiernos" y entrañas del walma» y de la historiavuelve su pensamiento -ensombrecido, 
pues - tratando de darle a cierta luz no cegadora, a una penumbra apacible. Con la que parece querer pretender reinstaurar otro medio más apto, menos violento, para que aquel logos spermatikos, la razón germinante en el puro "sentir», encuentre su lugar y su tiempo adecuado para concebirse, para nacer de otra manera que no sea la wacusadora», la enjuiciante, la categorial. No es, pues, el llamado por Hegel rarduo trabajo del concepton lo que está en cuestión en Zambrano, sino el modo de llevarlo a cabo, y sobre todo el hacerlo con "paciencia" y no con "precipitación", precipitando, asi, en la acusación, en el categorizar, a aquello mismo -a «todo cuanto en verdad ha necesitado para sern- que fue impulso y germen de la concepción, a pura ruina, o a simple instrumento, destruyéndolo o colonizándolo. Provocando así su permanente rencor.

Cabria decir que se ha invertido el propósito platónico de «salvar las apariencias" en este intento de salvar aquello que, realmente, no aparece (para el solo pensar) y que, sin embargo, es un insistente rumor, o un percutir de un silencio, que -desde "Ciudad ausente" (1928) - se vincula a la "Música calladaw de san Juan de la Cruz; o, ya en Claros del bosque, de «Aquello invisible que pasa sólo rozando" y dejando en su huella una herida, "la sombra del animal que huye, ciervo quizá también el herido" 14 ("ciervo vulnerado" decía san Juan de la Cruz). Rara pregunta esta - de no ser por lo sólita que ha sido, aunque sólo, acaso, en la mistica, o en los pensares a ella emparentados- que quiere ser ella misma como una herida, u horadación, de la clásica pregunta filosófica. Una pregunta, pues, que de un Jado no es un acusar o cuestionar, para fijarla, a la realidad, sino una remisión, un reenvio del preguntar a su foco primero hecho de la problematización de la agonfa en que acaba resolviéndose (tras el asombro) el pasmo inicial del hombre ante lo que ni siquiera sabe aún denominar como «mundo». Un ir trans-cendiendo, paso a paso, grado a grado, la crisis de la filosofía, sus evidencias, sus categorfas, sus problemas primeros, hasta el momento mismo en que la pregunta irrumpió en un orden de temores y adoraciones. Pues, toda pregunta - se dice en El hombre y lo divino a proposito de la primera pregunta de Tales de Mileto- indica la pérdida de una intimidad o la nuptura de una adoración. Y en este irse dejando atrós (tras-ladando y trans-cendiendo, y descendiendo y reencendiendo viejos rumores) las que Zambrano considera son reducciones y avasallamientos, y violencias del pensamiento filosófico, se demorará esta escritura en las huellas, en las ruinas, intentando abrir "poros" para que eso "que hay, pero que no es" (dira orteguianamente), por no disponer del pensamiento que lo ampare en el ser, pueda también ver la luz y sonar. Y aquí «los sueños» -la investigación crucial a la que me refería antesocupan el eje de esta pesquisa. Ellos son la noticia que permanentemente nos encontramos, por en medio de la Historia, de los aconteceres del vivir consciente, de lo que hay y no es, o es medio-ser, o fantasmas del ser, "Monstruos" siempre, sean amenazantes o salvadores, de lo que pasándonos no acaba de pasar, no acaba de hacerse, o darse en, historia; por no acabar de consumirse, 0 ni siquiera de darse realmente a ver, por no acceder al nacimiento en la conciencia. La teorización que Zambrano realiza del «despertar» está transida y guiada por su intención de descifrar, no el "contenido" de los sueños, sino su forma, ellos mismos como medio de visibilidad, de conocimiento, del acontecer. Enigmas 
los sueños, cifran su secreto sólo asequible a una cierta reconducción mistérica. A una cierta umántica» más que semántica. A un cierto darles esquemas, y aun estructuras significantes "proféticas", adivinadoras, más que "semióticas", a sus ininterrumpidos signos. Ciencia de los indicios, de la adivinación, la pre-filosofica indagación de Zambrano - yéndose al envés y a la "carnalidad", o encarnacion, o gestación, de la idea, a sus preformaciones- habrá de sustentarse en "otra lógica» que la categoriạl aristotélica, e incluso que la ya fijada en la lógica de la identidad, por Parménides; lógica que será más acorde con el que denomino modelo Heráclito, fluyente y oracular. Otra lógica que horada también los usuales modos "retóricos» (los ya inducidos por los sofistas, por el propio Sócrates y por Platón) y que, incluso, intenta "superar» toda dialéctica. Que buscará irse hacia ciertas fuentes musicales de contacto con el mundo, o los mundos, o sus diversos planos; con cuidado, con tacto y con los demás sentidos, centrándolos en un arcaico "sentir", para el que sentir, orr, percibir, atender y entender nítidamente $-y$ aun el tan místico "saborear"querrán ir unidos. $Y$ estableciendo puentes, mediaciones, significativos con los diversos ámbitos -o suertes, o Moiras - que desde el pensar mítico abrieron la posibilidad de ser discernidos como uelementos", como principios "arcaicos" de la fisis.

\section{Némesis musical y apólogos}

Este hontanar musical es netamente apolíneo y dionisíaco conjuntamente, hermanadamente. Es la forma alternativa que tiene Zambrano - "su estilow filosófico- de escribir y pensar, que irá transgresora y transcendentemente derivando hacia una fragmentación atonal y serial de la escritura que, a su vez, nos contara -nos "mitificara"cierto canto, en respuesta a la pregunta que, ella misma, se hizo en 1934: "¿Por qué se escribe?", artf́culo que es -en consonancia al primero en que se reflexiona sobre la música ( "Falla y su "retablo"», 1933)- su primer intento de escribir "musicalmente», su primer arte de la fuga, donde comienza a practicar lo que he denominado la *errancia impasible». Una especie de wobediencia" a un logos que se reparte bien por las entrañas. Es el sentido literal y etimológico de Némesis (raiz, nem: repartir, trasladable a su sentido derivado "comunicar" con medida, con justicia, "distribuir"). Se trata, pues, de una especie de Némesis musical mediante la que esta pensadora desgrana en sus "suertes", "Moiras" y destinos las operaciones de la logica. $Y$ es cn esta atomización y relativización donde, acaso, este filosofar muestre su máxima singularidad y, posiblemente, sus mejores virtualidades. $Y$ es ahi donde este geométrico reparto se numera sostenido por kel inimaginable corazón del tiempon; ${ }^{15}$ donde, prosigue ella, sviene a quedarse todo lo que ha pasado, todo lo que pasa sin poder acabar de pasar». Con lo que esta filosofía revierte a ser una geometría musical en pos del justo modo de escuchar. el lugar donde se abren una multiplicidad de tiempos, o una serie de ellos, que andan mezclados e uindiscernidos", en una especie de velocísimo dia-pas-on que a todo ser humano le pasa, le acontece, o más bien le hace pasar por todo el acontecer, sufrirlo. $Y$ estas Némesis y geografías musicales lo que intentan es cumplir la tarea de unas numeraciones del espacio y localizaciones del tiempo en unas "armonias" y "sincronizaciones», unas simbolizaciones acordadas del espacio-tiempo que se erigen, como ella dice del dios 
Apolo, en el ucentro del oír". Pero lejos de ser un «absoluto", ésta es, a modo de, la ley de la relatividad vigente en toda la forma mentis de Zambrano. Sus "leyes": "ética" del permanente irse haciendo, "genética" del irse naciendo y alógica" del irse pensando. Movimiento éste del pensar que habria de asumir a los otros dos, ética y genética, por librar de que los "conceptos" ni siquiera puedan "comenzar a ser concebidos agotado el germen del sentir que les corresponde».16 Asi pues, esta horadación lo es -en su diferida, suave, pero vigorosa apertura del espacio y del tiempo, en su vaciar planos, máscaras y múltiples espesas capas que, sin más, impiden "hacer» por falta de verdadero "nacer" llevando a la razón a ser el espectral esquema paralelo y escindido de la "vidas, sin roce alguno con ella- en función de spurificar" de opacidades y obstrucciones que impiden -que crean una barrera- hallar los gérmenes primeros del sentir, que son también los del discernir. Y para ello Zambrano propone una operación, que es su más arriesgado intento $-\mathrm{y}$ el más difícil de pensar- consistente en "simbolizar", en hallar un cauce, se diría, vibratorio, único para los diferentes ámbitos antes que categorías del espacio y del tiempo, mediante la fusión de sus expresiones respectivas, el número y la palabra. Una reconciliación del kespiritualismo" pitagórico con el "fisicismo" jonio resuelto en «lógica» en Aristoteles. "Se trata de una acción que se abre como la armonía, algo que se hace y se está haciendo sicmpre, desde allá y desde acá a la vez, cumplimiento milagrosamente matemático, incalculable como el de la armonfa. Manifestación de la armonía esta sincronización. Mas poco puede saberse de ella, apenas esa nada con que designamos a lo que condiciona lo incalculable. Logos y nú- mero al par."17 Este "apenas nada", "incalculable» logos-número, desde su relatividad, sólo va a pretender ser una sucesión de rumores, los muy inmediatos, y los muy lejanos, que fuesen como "una profecía del cumplimiento final, de la doble entrega del más allá y del ahoran. ${ }^{18} \mathrm{Y}$ es este fruto del tiempo -del vivido abriendole poros hasta sus más recónditos gérmenes- el cumpli* miento de los más débiles y apenas formulados presagios. Némesis y geometria musical obtenidas por una horadación y que parecen abrir - desde luego más allá, y más acá, del puro conocimiento discursivo, por su "fusion", o mejor, inmersión, en una "matemática" generativa - un conocimiento vaticinador desde las penumbras habitables a que quiere llevar las «entrañas», que serian entonces discernidas entrañas que hablan desde sus "números inconscientes" (aquellos números inconscientes del alma, según Leibniz), que se significan, pues, musicalmente. Una especie de apólogos si quisiéramos condensar (poéticamente, se entiende), de una parte la "mezcla» de logos y Apolo, de otra, el logos con el estricto sentido del prefijo procedente de la proposición griega apo: punto de partida y alejamiento. Pues esta es precisamente la labor que se pretende realizar en esta meditación que acaba por constituirse en una dialógica entre estos polos del logos y el número en un acuerdo o acorde armónico de espacio y tiempo. Conformando, así, su típico vaivén entre la lejanía y la cercanía, y de parte de la primera entre el arriba, el afuera, lo celeste, la transcedencia, lo transhistórico, lo extraterritorial, la ligereza (la elasticidad), el extasis, la Mirada remota, en suma; y de parte de la "cercania", el abajo, los adentros, lo infernal, la inmanencia, la historia, la tierra, la gravedad, el "éntasis", en definitiva el Roce adivinatorio. Punto es- 
tricto de conexión de ambos lugares y tiempos es la propia y radical soledad, cabría decir que el más pasivo desprendimiento (de los avatares, oxidaciones y capas del «yo» socializado) el abandono a la pura obediencia, a un consentido sentir, que enlaza, analogiza en su más "oscuro corazón" a lo más otro (lo más transgredido, al punto de estar fuera de todo grado, de todo fundamento, de cualquier "sujeton) y lo más íntimo y propio (lo más inmanente $\mathrm{y}$ escondido, lo que da de sí en pre-sagios, en flechas y heridas apenas percibidas, o negadas o areducidas" por el pensar y la conciencia discursivas, pero que dejan indelebles rastros de sus dianas, de su doler). Este apologo tiene su sustento en un logos del adolorn, en un algos (dolor, en griego). Así se concitan Apolo y Dionisos; y, a su $v e z$, en ellos se imantan otras figuras arcaicas del acceso a la realidad (vivible, visualizable, decible y musicable) que se muestran en la hermanación de estos dioses griegos. ${ }^{19}$ Asimismo, estos dioses griegos servirán de foco interpretativo para otros mitos y estructuras simbólicas posteriores, como es - con carácter general- esa denominada por Zambrano "religión de la luz" y "no sacrificial», cuyas particularidades, $o$ detenciones, más relevantes serán Plotino, cierto gnosticismo cristiano, algunos hitos del benedictismo como san Bernardo de Claraval, el propio "catarismo", o Dante, Spinoza, el propio Leibniz, algunos decisivos "movimientos» de filósofos, exégetas y poetas del romanticismo alemán (sobre todos Schelling y Hölderlin), as (como la decisión originaria de Nietzsche (la más perseguida, abundada y ahondada por Zambrano, junto a las de Plotino, Spinoza y $M$. Scheler) y este último citado, que será, en definitiva, con su propuesta de «Hacia un saber sobre el alma», y su "Ordo amoris", el que orientará todo el horizonte filosófico de Zambrano, más allá del que le había abierto Ortega con sus razones «vital" e shistórica".

La gracia (la lira) y la violencia (el arco) de Apolo son puestos al servicio de la audición de las demandas de su hermano Dionisos, el siempre otro, el patético dios de unos permanentes morir y nacer: el dios oscuro, símbolo de los medio seres, de lo que no adquiere forma o se de-forma, de lo que no acaba de nacer y requiere de múltiples vidas y renacimientos. ${ }^{20}$ El dios del delirio sostenido por la música, que, al fin, viene a ser cosa de Apolo, a través de su hijo Orfeo. En las profundas reinterpretaciones que de Nietzsche se hacen, no es la de menor importancia ésta de la música "de origen infernal", pero de entraña y armonización celeste: "la música ${ }^{21}$ sale del infierno; no ha caido desde lo alto; su origen, antes que celeste, es infernal. Más tarde aparecerá "la armonía de las esferas". Pues la armonfa viene después del gemido y del encanto. Lo peculiar de Orfeo, marca y señal del alma griega, es que el gemido no es queja desesperada, imprecación, sino dulzura secreta, misteriosa dulzura que sale de las entrañas del infierno [...]. $Y$ esta dulzura y esta mansedumbre permitirán a la razón, a las razones, entrar en los lugares infernales; serán el puente que el alma mediadora tiende siempre entre la razón y la vida en su padecer infernal; entre el sufrimiento indecible $\mathrm{y}$ el logos [...], Ja música une en sí los dos universos o los senos del universo: el de los astros de cuyo movimiento descendió la matemática y el mundo infernal de donde nace el gemidon. Es en esta confluencia en la que hay que comprender el modelo de inter-rogación que Zambrano ofrece frente a la pregunta por "el ser de las cosas», incluso del «serm. 
Confluencia en la que también afluyen otros mados exegéticos "místicos" y "esotéricos" ulteriores a aquellas figuras griegas. Es el caso de ciertas concepciones gnósticas cristianas, algunos aspectos del budismo zen, y, sobre todo, ciertas transmisiones sufies que Zambrano encuentra "mediadas" por el islamólogo L. Massignon, a quien declarará, a partir de 1956, su único maestro.

Asi, esta apología -que lo es también, en sentido estricto, "defensa de la palabra», o "elogio del logos", de un logos que se incardina en la walabanza* y en la "adoracion", antes que en la pregunta que fija las cosas y, en definitiva, la defensa también de una "ética del pensamiento» que subyace a la misma violencia filosófica- es un delta de confluencias indagadoras de los mitos más arcaicos que yacen -0 mejor, subfluyen, pues se muevenbajo los motivos puramente kracionales» de reducción excesiva de la realidad. Y eso que veíamos en la nota 13 como abandonado en la "sombra" es precisamente el territorio desde donde se interroga, y los rumores allí usentidos» los que dan pauta temporal del cuándo, del tiempo que dirige ese interrogar. Y asi, si la pregunta espacial es el ruego de "¿adónde te escondiste?" - como en san Juan de la Cruz, y más de seis siglos antes de él, en Al-Hallâj- la cuestión temporal por excelencia se vincula a un qué, sí, pero un qué que es ("que quedan balbuciendo...") enteramente "personal" y umusical". La música - para este pensar-22 es prenda de no traición, «[...] la música cumple, se cumple, y escuchándola nos cumplimos. Aquel que la trae ¿qué es? ¿quién es?, un ser remoto, una pura actualidad del siempre». Imantado por igual por ese "¿adónde?", y el "¿quién?", que es el "cuándo" - cabría decir- de una eternidad, el filosofar de Zambrano se sume en una dolorosa, y aun trágica, dialógica sobre el pensar y el sentir, irresoluble en dialéctica alguna, ni siquiera unegativa", $y$ que sólo alcanza, pues, su "solución" en su puro fluir musical desde el roce adivinatorio a la mirada remota que lo produce en el dolor y lo sostiene en la gracia de la musicalidad. Como Apolo.

\section{Hacia algunas claves del encanto y el canto}

Tal intento de dotar a los "espectros» de su propia - la de ellos - carnalidad y terrenidad, es lo más especifico de esta incursión filosofica. $Y$ la más singular de sus operaciones en el seno mismo de la concepción a la que, apresuradamente, tantas veces se la adscribe: el pitagorismo. Confundiendo, de un lado, el, al parecer, elogio sin fisuras que la autora dedica a esa concepción -y especialmente en "La condenación aristotélica de los pitagóricosn- con su autoadscripción a ella; y de otro, corroborándose en ello, porque la propia Zambrano parece, asimismo, adscribir al pitagorismo a todos los filósofos que realmente le interesan (los mencionados antes). Pero se olvidan algunas, a lo que creo, importantes matizaciones. La primera es: lo que únicamente se elogia de los pitagóricos es su cuádruple invención de: alma - matemáticas - música - viaje infernal. ${ }^{23}$ Las cuatro condensables en "número". Pero en cambio, hay que decir que se pone «de parte» de Aristoteles en cuanto a afirmar la doble imposibilidad en que los pitagóricos se sitúan: de un lado, en cuanto a su escisión alma-cuerpo, y al olvido y renuncia a éste y a todo lo "carnal»; y de otro, en la imposibilidad a que abocan a su invento mayor, la "filosofía" misma, al reducirla a número, a ritmo y medida, a puras matemáticas o músi- 
ca, pero no dables en apalabran; un puro decir, serfa el pitagorismo, "musical y no logicon. $Y$ así, "si es el número el que conforma y expresa la estructura de la realidad, "de las cosas que son", todo quedaria en esquema; las cosas quedarian desencarnadas, si son cuerpos vivientes; descorporeizadas, si son materiales o cosas hechas por el hombre. Y el universo sería un tejido de ritmos, una armonía incorporea, que tal debió de ser la fe inicial de los pitagóricos ${ }_{2}^{24} \mathrm{Y}$ precisamente, toda la filosofía de Zambrano es un intento de volver a encarnar lo descorporeizado, lo esquemático, aunque $-\mathrm{y}$ esta es la paradojica cuestión- haciéndolo pitagoricamente, es decir, con el arte del tiempo, con sus números, ritmos y melodías, con las que el "alma» halla su encarnación, su propio cuerpo. En esta tarea es claro que se "va sirviendo" de aquellos pitagorizantes que, piadosamente, habria que decir, "descienden" hasta el cuerpo en una acción "compasiva", aunque algunos de éstos renegasen explfcitamente de la concepción cristiana de la compasión: así Plotino, así Spinoza y su real saber de las upasiones", unidamente al "nadie sabe lo que puede un cuerpon; así Nietzsche y su saber de las calumniadas "vida», "tierra" y «carne". $Y$ aquí la singular exégesis "cristiana" de Zambrano aparece nítidamente como el núcleo viviente de fusión del cristianismo con sus tan acendrados antagonistas: Plotino, Spinoza y Nietzsche lo fueron, como tantos otros autores y movimientos que Zambrano intenta "mediar» en su teoria (es decir "procesión") encarnacionista. "Desde la situación actual del conocimiento su destino (del pitagorismo) es el más paradójico que sea posible imaginar. Fue vencido por el pensamiento aristotélico a causa de no poder dar cuenta de la "naturaleza". Mas, cuando la naturaleza se hizo ase- quible al conocimiento humano, se hizo docil al número, según muestra la física matemática desde Galileo hasta la actual del espacio-tiempo, la física de la relatividad, más pitagórica aún [...]. La polimatía, el relativismo no resuelto de los pitagóricos, su aceptación del tiempo pueden estar a punto de declarar bajo otro nombre -como vencidos al fin-su oculto sentido." ${ }^{25}$ $\mathrm{Y}$ aquí, a lo que considero, esta pensadora está rozando directamente, por no decir ironizando, sobre el significado mismo del intento que es su obra filosófica. Pues ćsta parece empeñada en dar otro nombre - urazón poétican- y otra solución al relativismo no resuelto de los pitagóricos, a su oculto sentido. Y cierta devolución a la "polimatías me parece sea la que se realiza al expresar, de muchas maneras, que la razón poética ha de tener, no una. sino varias formas y generos literarios. $Y$ que, de forma tan nítida, su obra misma se "disperses en formas literarias distintas como son ciertos modos de "confesion", de "guia", de escrituras poéticas, fenomenológicas, de critica literaria, filosófica y pictórica, o peculiares incursiones en la "política" y en sus rafces míticas. Cuando no es una Filosofía de la mistica, como sucede en Claros del bosque, De la aurora o Los bienaventurados. $Y$, por ello, tantas veces cifrando en la más pura reflexión filosófica una plegaria, una inter-rogación entre la filosofía y la oración. Y parece cumplir así una especie de «liturgia» operante cuyos elementos básicos son la cadencia entre el puro pensar y los ritmos y melodias que suscita el sentir. Es asi, nuevamente, la música pitagórica la que asume un papel sonoro decisivo para comprender la vinculación semiótico-semántica de esta escritura que busca ser un discernimiento del sentir, cierta luz (así lo dijo Cervantes) para la sangre. Es 
decir, un pensamiento encarnado. Para el que habría que decir que Dionisos, y acaso antes de él, Shiva y los mitos chamánicos, se prosiguen en Cristo $y$ en el único Dios, "patético", doliente, del sufismo que "necesita" de la criatura para nacer y hacer nacer. Un pitagorismo "metódico", cuya precision ${ }^{26}$ va aportando al primigenio pitagorismo el propio rostro carnal que las centrañas» piden al alma a través del "tiempo". Un pitagorismo, pues, en un tiempo encarnado nuevo. El tiempo, hay que decir, "donde" no sólo el "alma", sino el rostro mismo del hombre (que es cuerpo y alma sin escisión) configuran un mismo anhelo de resurrección. Pero este es ya otro cantar, o propiamente el diapasón que da el tono para que se canten ya las notas exactas que constituyen ese otro cantar.

Porque lo que he realizado aquí no es sino una cierta afinación, o un trabajo preparatorio para, con ellos, mejor sumergirse en los dos puntos verdaderamente interesantes de este quehacer filosófico. Es decir, de un lado, cómo se establecen unos delimitados ejes simbolicos (seres míticos, animales, elementos, metáforas) completamente vinculados a connotaciones musicales; de forma que literalmente su escritura, al par que va pensando, "canta" las ideas desde las capas "inferiores" de la conciencia mediante un roce adivinatorio, y guiada en sus tres formas $-y$ respectivas conformaciones- primeras de la experiencia y la atención (lugar-espacio; hora-tiempo; emoción-conmoción) por una "mirada remota" que funciona como el punto extraterritorial del pensamiento, de un pensar y escribir sostenido «sobre el abismo por la músicas; de -digámoslo con la propia Gestalt- la "unidad de los sentidos" hacia la "totalidad de las formasm. De otro lado, se estable- cen como tres círculos concéntricos con aquellas tres formas (de aht los tres caminos: el de la inteligencia, el del deseo, el del anhelo, simbólicamente relacionados con sendas formas del cuerpo y con animales símbolos, y con notas musicales) en torno a un eje central que siempre vendrá dado por la conjunción de estos roce adivinatorio y mirada remota. Estos circulos y eje central conformarán el ritmo nuclear del hombre, su "personalidad" propia, el ritmo sonoro personal, su voz, que, a su vez, es expresión de la "melodía" que cada ser cela. Así, diré que, para este pensamiento, la melodía es la vida de la sombra.

\section{La melodía en la sombra}

Solo indicaré aquí, para concluir, algunas claves (si no he realizado mal el cálculo) que pudieran estar subfluyendo míticamente (y místicamente), como "música callada", al pensar de Zambrano y que hacen del saber no sólo una mediación teórica con los que ella considera los uotros" saberes perdidos por el puro afán dominador categorial, sino que también, y precisamente, tal mediación se ejercita a través de una escritura que busca las fuentes musicales del sentir -el "sonar» del corazón-que sustentan la armonización del hombre con los diversos planos del Universo.

Así, esta obra dibuja teóricamente -y practica musicalmente- una escala, cuyas caracteristicas esenciales serían: primero, las sólo discernidas, a través de "ruinas», "huellas" e «indicios", religiones «arcaicas" y orientales que confluyeron hasta los dioses griegos, y cuya interpretación permite que las califiquemos de "sonidos" chamánicos. En segundo lugar (y ya con entera precisión acústica, hasta el punto de ser perfectamente identificables sus 
sonidos en el sentido que para ciertas culturas "arcaicas" adquieren los ejes musicales "si-fa-re" -intuición, vida afectiva, arte trágico $y$, en general, el ritmo de la serpiente sacrificada, suyo símbolo es la espiral-y asi-fa-dow -el "puente místicon, mediador entre muerte y resurrección, cuyo símbolos esenciales son la vía láctea, el ciervo y el mar en llamas-y finalnente el eje "fa-la" que es el camino místico de la mujer desde Venus, a través de la serpiente verde "terrena", hasta aquel puente místico) la adanza de purificación: y los roces adivinatorios que suponen e inducen los hermanos Dionisos-Apolo (y también el entramado de las divinidades griegas, en el que destacan las figuras de la Medusa, Perseo, Atenea y Hermes) coincidentes, en sus símbolos, con el pleno dominio del Chamán-médico y con sus melodías litúrgicas. En tercer lugar $-\mathrm{y}$ son las notas más afinadas- la ya plena vía de la "compasión» a través de una cristología implícita que asume las anteriores características en un movimiento que calificaré de vaivén de descenso-ascenso, en el que lo más destacable es el impulso que los "inferos" y la "tierra" dan al propio ucielo". Aquí el sentido mítico del intervalo "si-fa" es decisivo, y esencialmente el sonido mediador "f» y los símbolos claves son acuáticos, en especial el pez mediador, y Geminis y los gemelos. Pero es en el cuarto eje musical donde aparece con mayor claridad el que denominaríamos «modelo filosófico-poético de la anatomia del hombre misticon y un auténtico zodiaco intelectual, en el que destacan tanto la posición mística de la mujer como el (subrepticio, pero decisivo) papel del "andrógino" primordial. Me estoy refiriendo a la intersección que se realiza, desde el simbolismo gnóstico-cristiano, de los ejes anteriores, como he señalado, sobre todo, de cierta "teopatía" del sufismo. Aquí el papel "alquímico» o condensador de san Juan de la Cruz es clave. Y se da lo que $M$. Schneider ${ }^{27}$ denomina coruz de tambores», es decir, el entrecruzarse de símbolos sonoros humanos y udivinos». Y es muy visible ya la reconducción de los caracteres "salvíficos" de divinidades ancestrales, de Apolo-Dionisos, de (explicitamente) Quetzacoatl, Cristo, y la "divinización" carnal sufí hacia el Dios del sendero, enteramente salvador desde sus ritmos cíclicos de destrucción y construcción, muerte y resurrección. El símbolo clave aquí es, naturalmente, "la aurora" y el tritono "si-f" (la quinta disminuida; y el simbolismo esencial del agua) conducente al círculo musical completo constituido por: $f a$, do, sol, re, la, mi, si, fa sostenido, do sostenido, sol sostenido, mi benol, si bemol, dispuesto en una espiral. Este es el mito que subfluye a la esperanza de "apocatástasis" que, a media voz, susurrándose casi (nunca dicho de modo explícito) canta, bajo las palabras, el libro $D e$ la aurora con sus geografía (explícita) y zodíaco (no tan implicito, pues hay un capítulo dedicado a los "animales» de la aurora) intelectuales en que Roce adivinatorio y Mirada remota han confluido hasta una region auroral que no es otra que la permanente danza de toda «la evolución» hacia la eternidad, mediante un consumado sacrificio que permitiría el comienzo de una religión de la luz. La aurora, de nuevo, de una adoración.

Obviamente, entonces, uno de los problemas sustanciales que plantea esta escritura es la - al parecer inacabable- resolución antropologica de las conexiones entre mito y música, $\mathrm{y}$ de los apoyos que la propia palabra puede encontrar en la "musicalidad", sin incurrir en una permanente e irrebasable heterogeneidad. Es decir, en el 
traspaso ilícito a otro género - la aristotelica "metabasis eis alogenos"-, o el mal uso de las «metáforas», en este caso «musicales», para intentar discernir y practicar una "palabra liberada del lenguajen, a lo que, de modo así dicho, se dirige todo el decir de esta pensadora. Baste señalar, por el momento, que el roce adivinatorio y la mirada remota con que se intentan "posar" (y habrá que discernir también que no sea mera "pose", sino una experiencia real bien expresada) las palabras, más allá de su "cosificación", más allá de su violento avasallar la realidad, parecen querer ser unos percutir y repercutir admirativos, donde la propia "veneración" se erige en clave del pensar. Esta es la grave (o elástica) dificultad que planea no solo sobre la propia escritura de esta autora, sino que parece estar interfiriendo en casi todos los escritos que sobre ella se han hecho, abocándolos (quizá también a éste mío) a ser "malas" (por erradamente explícitas $\mathbf{u}$ opacamente glosatorias) transcripciones que ni dicen, ni ocultan, ni indican y ni siquiera rozan ni remotamente la mirada que tratan de hacer ver, ni la sintonía que quisieran hacen oír. Acaso - se nos sigue avisando- de lo que no se puede hablar es mejor callar. Callar y cantar, si es que aún fuese posible.

\section{NOTAS}

1. Para esta y las demás referencias de artículos y libros, véase la $\times$ Nota bibliográfica.

2. De la Akrora, p. 81, y en general toda la parte tercera dedicada a la palabra y especificamente el fragmento * El lenguaje y la palabra*.

3. Ibidem, p. 80 .

4. Vid. Claros del bosque, pp. 81-83.

5. Ibidem, p, 17.

6. Vease la nota introductoria a la edición de 1987 de Hacia at saber sobre el alma, Madrid, Alianza, pp. 9-30.

7. P. 18 .

8. P. 133 .

9. Claros del bosque, p. 123.

10. Ibidem, p, 17.

11. El puro conatus de a permanecer en el ser*, segín Hobbes y Spinoza, y del que Zambrano parte para estas cercantas, mientras que la lejania de la mirada sustentadora es en ella exegesis de Plotino y de una amplia gama amística

12. Ast en el Diwan d'Al Hallaj del siglo $x$ (de Fariddudine Attar [trad. y ed. de L. Massignon], Paris, Libraire orientaliste Paul Geuthner; 1955) se lee: Ton image est dans mon oell, ton memovial sur mes levres, ta demeure en mon coeur, mais on te caches-tu donc?. Luego veremos la importancia, para Zambrano, tanto de este texto como de su traductor, L. Massignon.

13. $\mathrm{Ha}$ sido una especie de imperativo de la Filosofía, desde su origen mismo, el presentarse sola, prescindiendo de todo cuanto en verdad ha necesitado para ser. Mas lo ha jdo consumiendo o, cuando así no lo conseguia, lo ha dejado en la sombra, tras de su claridad (p. 15).

14. Claros del bosque, p. 17

15. Ibidem, p. 47.

16. Ibidem, p. 139.

17. Ibidem, p. 45 .

18. Widem, p. 46 .

19. Así se dice en claros del bosque, p. 147, refiriénclose al modo adecuado de visión que se trata de ofrecer: «Otros medios de visibilidad que su mente y sus sentidos mismos reclamen por haberlos posetdo algund vez poeticamente, o litúrgicamente, o metafisicamente». El subrayado es mío.

20. El dios, según Zambrano, contribuye a crear la imagen de Apolo y encuentra un medio de hacerse audible en sus oráculos. La propia pitonisa - se nos recuenda- masca la hiedra en sus trances.

21. El hombre y to divino, p. 109; la ultima parte de la cita es de la p. 113 .

22. Claros del bosque, p. 97.

23. Invenciones que, en realidad, se explican como la explicitación religioso-filosofica de un modo ancestral de sentirse en el mundo, que aún se manifiesta en los orfico-pitagóricos.

24. El hombre y lo divino, p. 75.

25. Ibidem, p. 117.

26. El enunciado con ese titulo en Claros del bosque, p. 39, y en Notas de un método, passim.

27. El origet musical de los animales simbolos, Barcelona, CSIC, 1946, p. 187. 


\title{
NOTA BIBLIOGRAFICA. OBRAS CITADAS DE MARfA ZAMBRANO
}

"La ciudad ausente», El Manantial (Segovia). n." 4 (julio-agosto 1928).

"Falla y su "retablo"», Hoja Literaria, n." 3 (matzo 1933).

"Nostalgia de la tiema*, Los Cuatro Vientos (Madrid), n." 2 (abril 1993), pp. 108-113.

"¿Por qué se escribe?*, Revista de Occidente (Madrid), t. XLIV, n." 132 (junio 1934), pp. 318-328; en Hacia un saber sobre el ama, Buenos Aires, Losada, 1950; y en Madrid Alianza, 1987.

* Hacia un saber sobre el alma*, Revisia de Occidente (Madrid), t. XLVI, n." 138 (diciembre 1934). pp. 261-276; en Hacia ut saber sobre el alna, Buenos Aires, Losada, 1950; y en Madrid. Alianza, 1987.

*Filosofía y poesfax, Publicaciones de la Universidad Michoacana (Morelia, Mexico) (1939); en Obras remidas, Madrid, Aguilar, 1971, Col. Estudios Literarios; y en Mexico, FCE, 1987.

El hombre y lo divino, Mexico, FCE. 1955; y en Madrid, Siruela, 1992.

Claros del bosque, Barcelona, Seix Barral, 1977. De la aurora, Madrid, Turner, 1986.

Notas de un metodo, Madrid, Mondadori, 1989.

Los bienavennurados, Madrid, Siruela, 1990.

Los suetios y el tiempo, Madrid, Siruela, 1992.

\section{Estrategias narrativas en la construcción de la identidad}

\author{
JOSÉ MIGUEL MARINAS \\ Instituto de Filosofia, CSIC
}

Es en la frontera donde la identidad queda más definida,

Discurrir sobre la identidad es una práctica que, además de otras características propias, ha experimentado un desplazamiento fundamental. Si LéviStrauss, en su célebre seminario, ${ }^{2}$ afirmaba ya en los setenta que el momento era bueno, precisamente por lo pasado de moda que caracterizaba al "topicos de la identidad, la situación actual supera la ironía del maestro para enfrentarnos con una nueva vigencia de aquel tópico. Los procesos de redefinición conflictiva de las identidades en el presente hacen de su reflexión y debate algo que convoca a los gremios -incluido el de especialistas en modas- y, a la letra, los desborda.

Una de la vías reflexivas sobre este campo de problemas, la que analiza los procesos de las moralidades y los estilos de vida, incide especialmente en las formas discursivas de la elaboración de las identidades. ${ }^{3}$ Y ello en la medida en que los sujetos contemporáneos, en sus posibilidades de autonomía, se definen entre escenarios y relatos múltiples. La cuestión de la identidad se desplaza claramente, y no sólo en el campo del análisis de las moralidades, desde un abordaje onto-antropológico hacia una perspectiva sociológica ${ }^{4}$ y discursiva.

Pero esta perspectiva no obedece a una simple mutación en el instrumental analítico, sino a un cambio del contexto del objeto mismo. La multirreferencialidad de la identidad contemporánea, el hecho de que origen, genero, clase sean categorias en definición continua y ninguna de ellas por sí sola proporcione un relato, un referente na- 